\title{
Excitation states of Bose Einstein condensate coupled by time-dependent potential
}

\author{
T. B. Prayitno
}

Department of Physics, Faculty of Mathematics and Natural Science, Universitas Negeri Jakarta, Jl. Pemuda No 10, Rawamangun 13220, Jakarta, Indonesia

Corresponding author: trunk_002@yahoo.com

\begin{abstract}
Abstrak
Pada makalah ini telah dirumuskan tingkat-tingkat eksitasi dari persamaan Gross-Pitaevskii satu dimensi yang menggambarkan dinamika uap Bose-Einstein dengan mengganggap bahwa persamaan tersebut adalah sebuah persamaan osilator kuantum makroskopik. Dalam kasus ini, kami mengambil persamaan GrossPitaevskii yang tergandeng dengan fungsi bergantung waktu yang dianggap sebagai sebuah potensial eksternal. Potensial tersebut menciptakan pengaruh penguatan atau pelemahan dari perambatan pulsa di dalam serat optik nonlinear dan pengaruhnya telah diamati sebagai soliton terang atau gelap melalui hasil simulasi. Di dalam makalah ini, teori perturbasi bergantung waktu telah digunakan untuk mendapatkan tingkat-tingkat eksitasinya dan akan ditunjukkkan pula bahwa tiap-tiap tingkat tersebut mempunyai koreksi energi yang berkaitan dengan potensial eksternal yang bersangkutan. Meskipun tiap-tiap tingkat eksitasi tersebut telah didapat, persamaan differensial untuk koefisien-koefisien yang bersangkutan harus diselesaikan untuk mendapatkan gambaran lengkap dari solusi fungsi gelombang umum.
\end{abstract}

\begin{abstract}
We have formulated the excitation states of one-dimensional Gross Pitaevskii equation representing the dynamics of Bose-Einstein condensate, by treating the equation as a macroscopic quantum oscillator. In this letter, we concern at the Gross-Pitaevskii equation coupled by time-dependent function as an external potential. The potential itself creates the gain or loss effect of pulse propagation in nonlinear fiber optics and its effects have been observed as a dark or a bright soliton by simulating the equation. This time, we apply the time-dependent perturbation theory to obtain the excitation states and we also show that each excitation state has the energy correction corresponding to the external potential. Although we can formulate each energy state, one has to solve the differential equation for the coefficients if one wants to know the complete description of the general wave solution.
\end{abstract}

\section{Keywords}

Excitation states, Gross-Pitaevskii, Bose-Einstein condensation, gain-loss potential

\section{Introduction}

It has been well-known that the verifications of Bose-Einstein condensation (BEC) have been attracting many physicists to formulate the appropriate mathematical model. The verifications were coming from the experimental results by atomic cooling using sodium, rubidium, and lithium [1]. Besides, these results lead to develop the applications, for the best example how to built the atom laser and how to determine the best laser beam [2]. It has been noted that Gross and Pitaevskii have proposed the model in the case of discussion on weakly interacting bosons at very low temperature by atomic cooling and trapping. The first model is well-known as the threedimensional Gross-Pitaevskii equation (GPE). Some literatures and papers have been published to review the characteristic of GPE and then compare it with some experimental results [3-5]. Although GPE has been well built, the equation has been widely explored by applying the cylindrical symmetry to reduce three-dimensional GPE into one-dimensional GPE [6-10]. The interesting simulations have 
shown that the dynamical condensate can be represented as a stable wave, so called soliton which can be dark or bright which propagates in the vertical axis. Since the GPE itself is nonlinear Schrödinger equation (NLSE) with pseudo potential, the solution like soliton has unique characteristics. Some authors have deeply considered the NLSE and founded that the equation has been used to consider not only in atom laser, but also in some areas of active researches, for example pulse propagation in nonlinear optics and twin-core optical optics [11-14].

Some authors have compared the theoretical properties and experimental results by numerical method since the GPE has no analytical solution, except if one considers the Thomas Fermi approximation [8, 10]. By developing variety of other experiments, especially in atomic cooling and trapping, the ordinary GPE needs an extension to verify the experiment results. In Ref. [15], authors have extended GPE by adding time-dependent potential to explore the gain-loss aspects in pulse propagation in collapse-revival of the condensate. Although the above equation has no analytical solution, they can interpret the final results that it creates the soliton solutions by determining the ansatz solution of wave function and choosing the appropriate the potential. There is an interesting case in GPE, that is, for the small aspect in the nonlinear term, the GPE reduces to one-dimensional macroscopic quantum oscillator as in the ordinary quantum mechanics. Therefore, it is possible to construct all energy level states in GPE coupled by time-dependent potential by applying time-dependent perturbation theory by assuming that not only the nonlinear term should be small but also the time-dependent potential.

To obtain the excitation states, we use the similar method proposed by Kivshar et al. [8] who suggested that the general solutions of one-dimensional GPE can be obtained by applying the linear superposition of normalized eigenfunctions in macroscopic quantum oscillator. In this paper, we make some relevant assumptions and appropriate initial conditions in order to formulate the level energy states and the expansion coefficients. However, to obtain the analytical solution of the coefficients, one must solve the differential linear equation since all the coefficients is time-dependent. We also prove that each coefficient has its differential equation since it depends on even or odd eigenfunctions.

We organize this paper as follows: in Sec. 2, we transform three-dimensional GPE using dimensionless variables into onedimensional GPE. Next, we apply our onedimensional nonstationary GPE which has been obtained in the previous section to derive some excitation states in Sec. 3. Finally, in Sec 4, we state our conclusions based on the previous results.

\section{Methods}

This time, we initially reduce three-dimensional GPE into one-dimensional GPE by transforming all coordinates and the wave function, and finally using the cylindrical symmetry about the vertical axis. Some authors has written the evolution of the condensate wave function, trapped by three-dimensional anisotropic function, and containing the time-dependent potential describing gain or loss effect as [15] $i \hbar \frac{\partial \Psi}{\partial t}=-\frac{\hbar^{2}}{2 m} \nabla^{2} \Psi+U|\Psi|^{2} \Psi+V(\vec{r}) \Psi+i \frac{\eta(t)}{2} \Psi$

where $\Psi=\Psi(\vec{r}, t)$ is the condensate wave function, the atomic interaction is represented by $U=4 \pi \hbar^{2} a / m$ and is proportional to positive or negative $s$-wave scattering length $a$, $V(\vec{r})$ is the anisotropic parabolic trapping potential obeying 


$$
V(\vec{r})=\frac{m}{2}\left(\omega_{z}{ }^{2} z^{2}+\omega_{r}{ }^{2} r^{2}\right),
$$

where $r^{2}=x^{2}+y^{2}$ and $\eta(t)$ represents the time-dependent external potential called gainloss term.

Here, we have used the cylindrical coordinate system with the usual definition $\vec{r}=(r, \varphi, z)$ and state that $\omega_{z}$ represents the frequency along $z$ direction and $\omega_{r}$ describing the frequency along radial direction. To reduce the above three-dimensional GPE in Eq. (1) into one-dimensional GPE, we initially scale the cylindrical coordinate system into dimensionless coordinates $\rho=r / a_{0}$ and $s=z / a_{0}$, and then we also transform the time coordinate, the wave function, and the external potential by the following relations $\tau=\omega_{r} \lambda_{z} t / 2$, $u(\rho, s, \tau)=\Psi(r, z, t) \sqrt{a_{0}{ }^{3} / N}, \quad$ and $g(t)=i \eta(t) / 2 \hbar \omega_{r} \lambda_{z}$. Some authors have defined and written some physical quantities as follows $[6,16]$ : the length of harmonic oscillator $a_{0}=\sqrt{\hbar / m \omega_{r} \lambda_{z}}$ with $\lambda_{z}$ is the quotient between $\omega_{z}$ and $\omega_{r}$, and also assumed very small $\lambda_{z}<<1$, the number of interaction bosons in trapped in the parabolic potential is represented by the normalization of its wave function $N=\int|\psi|^{2} d^{3} \vec{r}$. By applying all the above transformations, we rewrite the GPE in Eq. (1) in dimensionless equation as [17]

$i \frac{\partial u}{\partial \tau}=-\nabla^{2} u-Q|u|^{2} u+\left(s^{2}+\rho^{2} / \lambda_{z}^{2}\right) u+g(\tau) u$

where we have defined $Q=-8 \pi N a / a_{0}$.

To get the final purpose, we have to separate the appropriate variables by defining the new function. Kivshar et al. have suggested that the final function should be written as [8] $u(\rho, s, \tau)=\phi(\rho) \varepsilon(s, \tau) e^{-2 i \gamma \tau}$.

In addition, Kivshar et al. have also chosen that the solution for $\phi(\rho)$ is

$$
\phi(\rho)=C \exp \left(-\gamma \rho^{2} / 2\right),
$$

where $C=\sqrt{\gamma / \pi}$ since one of the two differential equations which has been obtained is well-known as the differential equation of quantum harmonic oscillator written in polar coordinate. By this fact, after inserting the solution in Eq. (5) into Eq. (3), we obtain onedimensional GPE written as

$$
i \frac{\partial \varepsilon}{\partial \tau}+\frac{\partial^{2} \varepsilon}{\partial s^{2}}-s^{2} \varepsilon+Q|\varepsilon|^{2} \varepsilon-g(\tau) \varepsilon=0 .
$$

Here, we have adsorbed the obtained constant in the nonlinear term into $Q$. If we strongly observe the Eq. (6), it is clear that onedimensional GPE is a kind of nonlinear Schrödinger equation (NLSE) coupled by external potential representing by parabolic trapping potential and gain-loss potential.

\section{Results and Discussion}

In this section we concern to derive each excitation energy level of the one-dimensional GPE which has been written in Eq. (6). Although the one-dimensional GPE is a kind of NLSE, the equation can be also considered as onedimensional quantum harmonic oscillator if one assumes that the nonlinear term and the function of gain-loss term are very small. The consideration has been observed by some authors and they have also presented their numerical results in their papers $[1,8,16]$. However, in this paper we extend the suggestion proposed by Kivshar et al. to get our purposes. For the first step, we rewrite the important results proposed by Kivshar et al. Based on their suggestion, we extend that the 
time-dependent perturbative solution for onedimensional GPE can be written as [8]

$$
\varepsilon(s, \tau)=e^{-i E \tau} \sum_{n=0} B_{n}(\tau) \Phi_{n}(s),
$$

where $E$ is the total energy of system and $\Phi_{n}$ are the eigenfunctions of quantum harmonic oscillator written in dimensionless unit as

$$
\Phi_{n}(s)=\sqrt{\frac{1}{2^{n} n ! \sqrt{\pi}}} e^{-s^{2} / 2} H_{n}(s),
$$

where $H_{n}$ are the Hermite polynomials written also in dimensionless unit as

$$
H_{n}(s)=(-1)^{n} e^{s^{2}} \frac{d^{n}}{d s^{n}}\left(e^{-s^{2}}\right) .
$$

In addition, the energy level of quantum harmonic oscillator in dimensionless unit can also be written as $E_{n}=2 n+1$ for $n=0,1,2, \ldots$.

In our previous paper [17], it has been derived the ground state energy of the onedimensional GPE by applying the perturbative solution using the above equations. This time, we extend our case to obtain some excitation energy levels by applying the same procedures. The procedures are applied as follows: we substitute the solution in Eq. (7) into Eq. (6), then we multiply both sides by the conjugate $\Phi_{m}{ }^{*}$, and finally we integrate over all space. We obtain the final result as [17]

$$
\begin{array}{r}
B_{m}(\tau)\left(E-E_{m}-g(\tau)\right)+\dot{B}_{m}(\tau) \\
+Q \sum_{n l k=0} B_{n}^{*}(\tau) B_{l}(\tau) B_{k}(\tau) \Omega_{m n l k}=0
\end{array}
$$

where $\dot{B}_{m}$ states the derivative of $B_{m}$ respect to $\tau$ and

$$
\Omega_{m n l k}=\int_{-\infty}^{\infty} \Phi_{m}^{*}(s) \Phi_{n}^{*}(s) \Phi_{l}(s) \Phi_{k}(s) d s .
$$

Now, we have completely obtained our materials to continue our discussions. To obtain each excitation state, we sign the index of $m$ in Eq. (10) started from one. Here we only describe first and second excitations, since other excitations can be obtained by applying the same procedures

- First excitation

By inserting the value of $m=1$ into Eq. (10) and assuming that $B_{1}>>B_{m}$ for $m>1$, we find the expression

$$
\begin{array}{r}
\dot{B}_{1}(\tau)=-B_{1}(\tau)\left(E-E_{1}-g(\tau)\right) \\
-Q\left|B_{1}(\tau)\right|^{2} B_{1}(\tau) \Omega_{1111} .
\end{array}
$$

To obtain the energy of the first excitation, we have to determine the appropriate initial condition. Since we only concern at the first excitation, we can assume that at $\tau=0$ our system is in the first excitation and $g(\tau=0)=g(0)$. So, by applying the condition we have to give the initial conditions as

$$
B_{1}(0)=\delta_{00} \text { an } \dot{B}_{1}(0)=0,
$$

we obtain our energy of first excitation as

$$
E=E_{1}+g(0)-Q\left|B_{1}(0)\right|^{2} \Omega_{1111} .
$$

Based on the fact that $\Phi_{n}$ consist of even functions (for even $n$ ) and odd functions (for odd $n$ ), we can solve the appropriate coefficients as

$$
\dot{B}_{n}(\tau)+B_{n}(\tau)\left(E-E_{n}-g(\tau)\right)=0 \text {, for even } n
$$

and

$$
\begin{array}{r}
\dot{B}_{n}(\tau)+B_{n}(\tau)\left(E-E_{n}-g(\tau)\right) \\
=-Q\left|B_{1}(\tau)\right|^{2} B_{1}(\tau) \Omega_{n 111}, \text { for odd } n
\end{array}
$$


- Second excitation

By applying the above procedures, we take the value of $m=2$ into Eq. (10) and also assuming that $B_{2}>>B_{m}$ for $m>2$, we find the expression

$$
\begin{array}{r}
\dot{B}_{2}(\tau)=-B_{2}(\tau)\left(E-E_{2}-g(\tau)\right) \\
-Q\left|B_{2}(\tau)\right|^{2} B_{2}(\tau) \Omega_{2222} .
\end{array}
$$

This time, we assume that at $\tau=0$ our system is in the second excitation and $g(\tau=0)=g(0)$

. So, by applying the similar condition we have the initial conditions as

$$
B_{2}(0)=\delta_{00} \text { and }
$$

$$
\dot{B}_{2}(0)=0 \text {, }
$$

we obtain our energy of second excitation as

$$
E=E_{2}+g(0)-Q\left|B_{2}(0)\right|^{2} \Omega_{2222} .
$$

Based on the same fact that $\Phi_{n}$ consist of even functions (for even $n$ ) and odd functions (for odd $n$ ), we can solve the appropriate coefficients as

$$
\dot{B}_{n}(\tau)+B_{n}(\tau)\left(E-E_{n}-g(\tau)\right)=0, \text { for odd } n
$$

and

$$
\begin{array}{r}
\dot{B}_{n}(\tau)+B_{n}(\tau)\left(E-E_{n}-g(\tau)\right) \\
=-Q\left|B_{2}(\tau)\right|^{2} B_{2}(\tau) V_{n 222}, \text { for even } n
\end{array}
$$

All the above coefficients can be solved both analytically and numerically by considering other initial conditions by observing the appropriate experiment results

\section{Conclusion}

We have formulated some excitations of energy state of GPE, containing time-dependent potential by applying time-dependent perturbation theory, by extending the previous work of Kivshar et al. [8] in addition, it is possible to construct the higher level energy and discuss it with various scattering length condensates, $a$, since the scattering length describes the interaction of atom condensates. Based on the final results, we conclude that it is possible to obtain the simulation of general wave function solution if we can solve analytically the differential equation for coefficients by finding the appropriate initial conditions. However, we also can solve them by extending the coefficients into power series using the Frobenius method. In addition, if one wants to compare the final results with the experimental results, one has to choose the appropriate time-dependent potential, for further discussions one can see Ref. [15].

Although we are not dealing with the simulation, we can predict that the graphical solution of the condensate density obtained by the absolute square of the general wave function solution should be localized. The prediction is based on the fact that eigenfunctions in macroscopic quantum oscillator used here, have actually Gaussian form. Finally, we hope that this discussion will stimulate the simulation efforts that can be useful to develop the application both in science and engineering, especially in nonlinear optics and atom laser.

\section{Acknowledgement}

It is a pleasure for us to acknowledge Reinard Primulando (PhD at William \& Mary University), Mutia Delina (PhD at Groningen University) and Riser Fahdiran (PhD student at T. U. Kaiserslautern) for sending us international papers to support this research. 


\section{Referentes}

[1] M. Holland, J.Cooper, Phys. Rev. A 53 (1996) R1954-R1957.

[2] Th. Busch, M. Köhl, T. Esslinger, K. Mølmer, Phys. Rev. A 65 (2002) 043615.

[3] F. Dalfovo, S. Giorgini, L.P. Pitaevskii, S. Stringari, Rev. Mod. Phys. 71 (1999) 463-512.

[4] L. Pitaevskii, S. Stringari. Bose-Einstein condensation. 1st ed. Oxford: Clarendon Press (2003).

[5] V.I. Yukalov, Phys. Part. Nucl. 42 (2011) 460-513.

[6] V.M. Peréz-García, H. Michinel, H. Herrero, Phys. Rev. A 57 (1998) 3837-3842.

[7] E.A. Ostrovskaya, Y.S. Kivshar, M. Lisak, B. Hall, F. Cattani, D. Anderson, Phys. Rev. A 61 (2000) 031601.

[8] Y.S. Kivshar, T.J. Alexander, S.K. Turitsyn, Phys. Lett. A 278 (2001) 225-230.

[9] R.A. Duine, H.T.C. Stoof, Phys. Rev. A 65 (2001) 013603.

[10] U. Al Khawaja, H.T.C. Stoof, R.G. Hulet, K.E. Strecker, G.B. Partridge, Phys. Rev. Lett. 89 (2002) 200404.

[11] W. Ketterle, Rev. Mod. Phys. 74 (2002) 1131-1151.

[12] Y. Shin, C. Sanner, G.B. Jo, T.A. Pasquini, M. Saba, W. Ketterle, D.E. Pritchard, M. Vengalattore, M. Prentiss, Phys. Rev. A 72 (2005) 021604.

[13] Y.J. Wang, D.Z. Anderson, V.M. Bright, E.A. Cornell, Q. Diot, T. Kishimoto, M. Prentiss, R.A. Saravanan, S.R. Segal, S. Wu, Phys. Rev. Lett. 94 (2005) 090405.

[14] V.I. Kruglov, A.C. Peacock, J.D. Harvey, Phys. Rev. Lett. 90 (2003) 113902.

[15] R. Atre, P.K. Panigrahi, G.S. Agarwal, Phys. Rev. E 73 (2006) 056611.

[16] F. Dalfovo, S. Stringari, Phys. Rev. A 53 (1996) 2477-2485.

[17] T.B. Prayitno, Makara of Science Series 15 (2011) 197-200. 